\title{
Talking back to theory: the missed opportunities in learning technology research
}

Sue Bennett ${ }^{\mathrm{a}}$ and Martin Oliver ${ }^{\mathrm{b} *}$

${ }^{a}$ Faculty of Education, University of Wollongong, Wollongong, Australia; ${ }^{b}$ London

Knowledge Lab, Institute of Education, London, UK

(Received 31 January 2011; final version received 14 September 2011)

Research into learning technology has developed a reputation for being driven by rhetoric about the revolutionary nature of new developments, for paying scant attention to theories that might be used to frame and inform research, and for producing shallow analyses that do little to inform the practice of education. Although there is theoretically-informed research in learning technology, this is in the minority, and has been actively marginalised by calls for applied design work. This limits opportunities to advance knowledge in the field. Using three examples, alternative ways to engage with theory are identified. The paper concludes by calling for greater engagement with theory, and the development of a scholarship of learning technology, in order to enrich practice within the field and demonstrate its relevance to other fields of work.

Keywords: theory; design; learning technology

\section{Introduction}

This paper poses the question: why should we be concerned with theory? To answer this, a review is provided of the ways in which theory has - and has not been engaged with in learning technology research. This is followed by three cases, in which different ways of engaging with theory are offered. The paper concludes by identifying ways in which work in this field frequently fails to engage with theory, and how this situation could change, creating a more dynamic relationship between theory and practice.

\section{Background: theory and pragmatics in learning technology research}

Theory has had a relatively small role to play in learning technology research to date. Mostly, research has focused on matters of practical implementation and design, largely driven by 'common-sense' assumptions about what technology can achieve, or - for many decades - by hype and excitement rather than evidence or theory (Mayes 1995). For example, reviews (for example, Conole, Smith, and White 2007) have shown that visible, tangible investment - typically purchase of hardware or software - has been the priority for funding over a 45-year period, not educational principles. Only later, if at all, has work followed that addresses the

*Corresponding author. Email: m.oliver@ioe.ac.uk 
patchy and inconsistent patterns of use that typically follow such investment. Such reviews make it clear that fashion and markets (Selwyn 2007), rather than principles or theory, remain the major driving forces behind much research, development and implementation work in this area:

Research has a tendency to follow policy directives and technological developments, rather than informing them [...] sadly there has been too much evidence of knee-jerk policy, which does not take account of evidence arising from research. (Conole, Smith, and White 2007, 53)

This gap is not only visible in relation to policy. According to Friesen (2009), research in this field generally treats theory and empirical work as separate, rather than as integral parts of the same endeavour. Friesen offers a useful conceptual framework for this discussion, identifying three different traditions of research. Drawing on Habermas, he distinguishes between instrumental (concerned with technical interests associated with work or production), practical (concerned with interpretation or meaning) and emancipatory traditions. He goes on to argue that only the instrumental is well represented in this field, and that the conspicuous absence of theory is an important indication of this:

To use the words of educational technologist Rob Koper [...] this research tends not to be 'theory-oriented,' but rather 'technology-oriented' in character. E-learning research, Koper (2007) explains, is not focused on "predicting or understanding events [in] the world as it exists" (p. 356); it instead seeks to "change the world as it exists" (p. 356; emphasis added). E-learning or technology-oriented research, in other words, attempts "to develop new technological knowledge, methods, and artifacts" for practical ends or purposes (p. 356). It is this applied, practical, and technological research that Koper (2007) says is ideally suited to e-learning. (Friesen 2009, 7)

Another indication of this pragmatic orientation can be found in Conole and Oliver's (2007) introduction to the field. They identify four groups of issues within learning technology research: pedagogic, technical, organisational and sociocultural. Arguably, using Friesen's categories, the first three of these could be classified as instrumental, and even the fourth could be viewed as a means to instrumental ends. Theory or even critique remains conspicuously absent.

This current situation reflects a long-term preoccupation with practical problems. Hawkridge's historical account of the development of educational technology as a field (2002) illustrates this. The review draws together previous reviews, meta-studies and content analyses, grouped by continental tradition and stretching back to work in the late 1960s. He describes how a North American tradition grew from instructional design, which was founded on objectivism and linked to industrial and military uses of systems analysis. As this grew through the 1960s and 1970s, it established connections to broader educational work focused on the curriculum and on the science of teaching. The result of these links was the development of programmed instruction: a pragmatically oriented technique for enhancing learning outcomes using behaviourist principles. A consistent emphasis throughout this period was on the scientific improvement of the practice of teaching, largely through automation. (A fuller account of this is offered by Saettler 1990.) Research in other English-speaking countries was strongly influenced by the North American tradition, drawing heavily on US texts. Systems-based 
approaches were also well represented in the United Kingdom; for example, in the work of Pask (for example, 1976). Although the role of theory has broadened since this early period, Hawkridge argues that the primary focus of learning technology research into this century has been pragmatic, concentrating on applications of new technologies and the pursuit of behavioural evidence of improved learning outcomes.

In spite of the growing popularity of qualitative studies of constructivist inspired learning environments since the early 2000s, which could have offered other models of research, this emphasis on practical applications persists and indeed has been periodically reinforced by commentary such as that of Reeves:

To realize the fullest potential for online learning, our methods of research and development must be fundamentally changed, but additional changes are needed. First, we must shift from a position that views learning theory as something that stands apart from and above instructional practice to one that recognizes that learning theory is collaboratively shaped by educational researchers and practitioners in context. Educational technology is a design field, and thus, our paramount goal of research should be solving teaching, learning, and performance problems, and deriving design principles that can inform future decisions. Our goal should not be to develop esoteric theoretical knowledge that we expect practitioners to apply. This has not worked since the dawn of educational technology, and it won't work in the future. $(2005,304)$

This continued focus on practical 'use-inspired' design research is promoted as 'socially responsible' (Reeves, Herrington, and Oliver 2005), to be valued above and pursued in preference to other forms of research. This view, advocating the type of learning technology research that should be done, limits possibilities for advancing the field. While design research works well for investigating the effectiveness of a particular design in practice, and so helps to inform instructional design theory, it has little relevance to non-design problems. Even the emergence of design research as a methodology - one with a "focus on advancing theory grounded in naturalistic contexts" (Barab and Squire 2004, 5) - has done little to change this, since its focus continues to be on "developing a profile or theory that characterizes the design in practice" $(2004,4)$, rather than on wider concerns. Reigeluth and Frick's (1999) distinction between instructional design theory and descriptive theories of learning is helpful here, drawing attention to the scope (and hence the limitations) of a design research focus. Seeing learning technology research as primarily - or even exclusively - occupied with developing and testing designs misrepresents the breadth of work actually being undertaken (Czerniewicz 2010).

To illustrate these wider concerns, Thorpe's review (2002) is helpful, since it is focused directly on theory and pedagogy. She describes how, over the previous decade, pedagogic thinking shifted from a focus on materials and instruction to social competence, collaboration and situated performance, mirrored by a shift in the theories used to justify the work from behaviourism to social constructivism. This account can be understood as raising some modest challenges to Friesen's critique, suggesting that practical and emancipatory research have in fact called instrumental 'progress' into question - albeit only for a few restricted areas of work - by suggesting that some changes may not always be seen as improvements. So, for example, Thorpe describes how accounts (many of which are related to positions such as constructivism) that celebrate increased student independence and autonomy can be critiqued as excuses for leaving students isolated and unsupported. This is not the 
kind of challenge that can be answered with more empirical data; instead it needs, we suggest, a position to be taken about what is desirable and why. In other words, it needs theorising.

This account illustrates how research in the field can focus on questions other than design. As Czerniewicz's review (2010) demonstrates, while instructional design is sometimes positioned as the 'core' of work in learning technology, the field is really too diverse and fragmented for such a claim to be credible. She points instead to evidence that theory is brought in through links to numerous other fields, and development "takes the form of new languages which offer fresh perspectives and a new set of connections, rather than integration with existing theories and approaches" (Czerniewicz 2010, 524). Treating theory as if it was simply and solely a foundation for applied design fails to represent the richness of work that can, and sometimes is, undertaken within this field. It leaves theory unchallenged - and often unquestioned - so that empirical work supports or illustrates theory, but is not seen to develop or even provide a basis for rejecting it (Cook 2002). Such work is possible, however, as the cases in the next section will demonstrate.

\section{Case studies of engagement with theory}

As argued above, much work in the field of learning technology either neglects theory or else operates in a derivative way, simply applying it. However, there are examples of kinds of work that show different forms of engagement with theory. Three examples are given here, showing how empirical work can develop theory; how theories and evidence can undermine claims and redefine design problems; and how theory can change the way that a phenomenon is understood.

\section{Case one: mutually informing theory and practice}

Richard Mayer's body of work on multimedia learning exemplifies a particular branch of learning technology research based on the kinds of psychological theories and approaches that have been popular since the early years of research into computer-based or computer-assisted learning. Over his career Mayer has produced an extensive body of work that has drawn on traditional scientifically based experimental methods to advance understanding about how interactive multimedia influences learning. Many well-recognised principles of multimedia design stem from Mayer's findings.

Mayer's research illustrates how empirical work can define, rather than apply, theory. It builds on the desire "to understand how people integrate verbal and visual information" (Mayer 1997, 4) as the basis for improving multimedia design; something that requires a twin focus on theory and practice. Mayer, describing his theoretical approach (1997), explains how this work built on previously established theories of cognitive processes, which he applied to the new environment of multimedia. The literature contains a series of more than 40 studies that are informed by previous results and incrementally develop refinements and extensions to that theoretical approach (for example, Mayer and Chandler 2001; Mayer and Johnson 2008; Mayer and Moreno 2003). While, at one level, this work fits within the traditional of learning technology research as informing the design of instructional software, it does this in a dialogic way. Theory does not simply inform design; Mayer's findings do generate design principles, but they also reshape the underlying theory. 
It would be easy to dismiss Mayer's work as 'out of step' with current thinking in learning technology research. For example, research into content-driven, direct instruction of the type with which Mayer was concerned has been replaced by a focus on constructivist approaches. Moreover, critics have labelled experimental methods in learning technology research misguided (Clark 1983) and pseudoscientific (Reeves 1993), arguing that learning is too complex to allow for the proper isolation of variables required by the scientific method. It is also claimed that experimental studies are conducted in environments so artificial that their findings have little relevance to real classrooms, and that researchers must over-reach in making claims about the wider applicability of their findings. Such criticisms have been important in establishing qualitative research as a viable and valuable approach; however, it ignores the status of Mayer's design recommendations: they are provisional and tentative, rather than being nomothetic laws, created to guide design rather than prescribe it. Problems that arise when using them in complex classrooms should therefore be fed back into the theory, allowing it to be refined, rather than being seen as evidence of its failure.

Mayer's work thus has something important to offer a discussion of the role of theory in learning technology research. Mayer has achieved a coherent, interconnected body of work that is informed in every way by the theory in which it is located, from its conception (building directly from unanswered questions raised by past research and under-developed theory), to execution (the methodologies used), and to interpretation (what it means in relation to the questions asked, earlier findings and future research). This work is narrow in its focus, and appropriately modest in its claims, limited to studies and applications of how people understand verbal and visual information in combination. However, Mayer's work demonstrates the kind of two-way conversation in which the empirical speaks to theory too, developing it. This kind of dialogue between empirical studies and theory is largely absent from learning technology research, according to the reviews provided above. Through this reciprocity, Mayer's theory seeks to explain phenomena, and observation of phenomena is used to test and develop theory. Through theory his studies connect to a wider body of related research on cognitive processes in computerbased learning. In sum, Mayer's work demonstrates how theory can inspire, frame and guide research that cumulatively builds knowledge in a highly focused area.

\section{Case two: reframing design problems}

Games and virtual worlds have become a popular topic within learning technology research, and much has been written about their educational potential (for example, McFarlane, Sparrowhawk, and Heald 2002). It is claimed, for example, that digital games have developed powerful and effective pedagogies that education would benefit from adopting (Gee 2005). In other words, games have developed design principles that could usefully be applied in educational contexts.

However, there are two problems with this. The first can be revealed by using other theories to re-interpret the situation. For example, cultural theory suggests that it may be wrong to think of this as a design problem at all. This conception of the situation rests on an assumption that may simply be inappropriate: that education is failing students and that games are "a kind of remedy [... so that the diseased, geriatric body of education can be treated through the rejuvenating, botox-like effect of educational game play" (Pelletier 2009). If this kind of 'treatment' account fails 
to hold - for example, because forced play is an oxymoron, and so requiring students to use games cannot credibly be seen as meaningful play - then the whole endeavour is misconceived.

Secondly, such 'hopes' are often perpetuated by claims about games' potential. These claims are based on popular perception rather than theory or evidence arising from specific examples of play (Squire 2002).

In order to rethink the relationship between games and learning, and avoid the tendency to discuss both games and learning in the abstract, a situated approach was developed to studying what people learned when they played digital games. Activity theory was used as the basis for this, since this allowed recorded performances to be characterised and analysed as purposeful, goal-oriented activities (Oliver and Pelletier 2006). The alternative - 'common-sense' accounts of 'potential' - was simply too vague to be studied and judged with any hope of credibility.

The theory of expansive learning (Engeström et al. 1996) positions learning as a creative, situated process in which social practices are adapted to cope with challenges or problems. Building on this, evidence of learning during play was generated by identifying breakdowns, such as failed attempts to progress through a level, and then looking to see whether there was evidence that this problem had been overcome. Where it had, the new approach to play was given a descriptive label and added to the expanded list of strategies used by the player. This resulted in specific, situated strategies (e.g. "spot unusual objects and click on them") and three broader categories that were positioned as different kinds of learning: learning to use tools skilfully, learning about objects and spaces within the game, and learning the tactics and strategies needed to progress through the game (e.g. how to identify and respond to 'set piece' encounters, even when these differed representationally). Subsequent work with a more complex game (Oliver and Pelletier 2005; Pelletier and Oliver 2006) provided evidence about transfer of strategies from previous play, but also about inappropriate transfer and of forgetting successful strategies. This meticulous building and categorisation of lists provided a credible and transparent evidence base for the claims that were made. Unlike earlier claims, these were empirically grounded and culturally specific; they showed how learning happened when playing digital games, but also showed how situated it was. This helped to explain why games could not simply be 'injected' into curricula (de Freitas and Oliver 2006).

Moreover, these studies did not simply apply theory to inform design. Conventionally, analyses using activity theory operate at the level of case studies, characterising the practices of a bounded group of actors over period of time, as (for example) in Engeström's Change Laboratories (Engeström et al. 1996). In the cases referred to here, however, the focus is on individuals playing games for a period of hours - a relatively 'micro' focus, in which the influence of community (e.g. designers, other players) is either absent or mediated by the software and hardware. The result of this is a focus on evidence of learning through changed behaviour something more akin to Skinner's Behaviorism than to conventional socio-cultural accounts of learning. While Oliver and Pelletier's work $(2005,2006)$ is case-study based, it uses this evidence to challenge widely-made claims; linking these to an established tradition of work by not only applying an existing approach in a new field, but also exploring, in a modest way, how the scope and utility of that approach could be developed. In this sense, it also provided an opportunity for dia- 
logue with the foundational tradition of work in which the theory had originally been developed.

\section{Case three: theory to frame research within a wider context}

Chen's (2010) PhD study into Chinese international students' experiences of online learning was prompted by a desire to frame a study of technology within a wider context. The research could have been conducted as a descriptive case study of the specific experiences of these learners of this type of online delivery, but theory allowed it to be conceptualised as a 'case' of something more general: a case of acculturation. This kind of reframing allows a study of technology use - something apparently only of interest within the field of educational technology - to be repositioned as relevant to an entirely new audience.

Current learning technology research includes many in-depth case studies of how a technology has been applied to education. Findings from these cases studies often consist of detailed descriptions, sometimes concluding with a list of emerging themes or issues. These have obvious practical value: when presented appropriately, such research supports the kind of "naturalistic generalizations" that Stake (1995) suggests can happen when readers compare a case study with their own experiences and draw conclusions.

However, there is usually little attempt made in the analysis of such case studies to draw conclusions of the kind suggested by Yin $(2009,43)$ that can "generalize a particular set of results to some broader theory". This is because this type of casestudy research is driven by an interest in investigating a practical problem (e.g. how to use blogs in higher education); a pragmatic focus that often has little connection with theory. As a consequence, particular cases have no way to 'speak' to a wider body of research. They remain bound to the particularities of the case context. This final example demonstrates how theory can allow a case study to be positioned as part of a wider body of work, as well as bringing coherence to the study itself.

In this case, the use of Berry's (1997, 2005) model of acculturation as an organising framework led Chen to explore what Chinese students 'brought' in terms of their assumptions about and past experiences of education in China (their heritage culture) to their experiences of Australian higher education (their host culture), as enacted in the online learning environments they found themselves in (contact between cultures). This illustrates the use of theory to structure the study; theory provided an orienting framework to shape data collection and analysis by providing a lens that determines which aspects of the context should be attended to and why they are important to understanding the phenomenon. Seen through Berry's model, the study focused on collecting data that could characterise the two cultures and the outcomes of their contact. In this way, the theoretical lens shaped the research design, and in so doing focused the researcher's attention on particular aspects of the context. As part of her analysis, Chen compared her results with the theory's predictions to determine how well the theory explained the outcomes of students an example of Yin's idea (2009) about how the empirical can 'speak' back to theory.

Chen further extended her analysis to draw on theoretical constructs from Bernstein (1977) and Maton (2006). The empirical work thus became a site in which previously unconnected theories were brought together; and by doing so demonstrated how theories from psychology and sociology can work in tandem to 
conceptualise different aspects of a phenomenon and overcome limitations in each. Furthermore, each construct came from a broader theory, although Chen drew on only what was needed and useful for the scope of her study.

This study thus demonstrates three things. The first is the value of theory in specifying and advancing understanding of a particular phenomenon. The second is the way that this individual study can be connect to broader concerns (in this example, acculturation of overseas students, how clashes in educational cultures occur, how different forms of knowledge and knowing are valued), not just remain of interest to those concerned with the specific context in which the study took place. Thirdly, it emphasises the partial nature of theories: rather than merely applying one and expecting data to conform to it, theories were judged for their explanatory potential and combined or extended as necessary. Chen (2010) demonstrates how this is possible within the scope of a $\mathrm{PhD}$, showing how the integration of theory is achievable and valuable even within a single study.

\section{Discussion}

As the initial review showed, the use of theory in the field of learning technology has, primarily, been about its application to solve practical problems. Where dialogues between studies and theory have occurred, these are mostly in the context of design - again, an instrumental end focused on pragmatics.

There is nothing wrong with pragmatic research - however, the examples provided here show that more is possible. Research in the field need not be defined by policy, technological developments or popular discourse. It is not always applied; and it is not always design oriented.

The examples here echo and develop the points made in Czerniewicz's (2010) review of research in the field. Research can draw on theories from psychology, sociology, cognitive science and education. More importantly, however, these examples show that theory is useful for more than just improving applied design practice. Instead, it has a role to play in creating a coherent, bounded scope for the work; thinking through what would count as credible evidence; managing and interpreting data; rethinking whether the problem has been framed correctly in the first place; situating the study in relation to wider concerns and issues, such as work outside the immediate field; and developing the theories themselves.

The examples have also highlighted that not all theory is ready to apply; some requires working through, adapting or selecting from in order to make it relevant and practical. As all three of the examples above show, use of theory requires taking a position: it requires judgement about which parts are useful, which are unnecessary, and which need development. In other words, the use of theory requires engagement, not just application. There are useful parallels to be drawn here with at least three of Boyer's categories of scholarship (1997): discovery; integration; and application. (The case for teaching is arguably less direct.) A scholarly approach to research in learning technology should build knowledge, including new theories; integrate work from different disciplines in a thoughtful way; and apply it to practical problems and concerns.

Calls to restrict research in the field to applied, design-based, problem-solving studies, in which theory is applied rather than challenged or developed, limit the kinds of work that are valued. As Czerniewicz (2010) identifies, such calls are ideological: they legitimate particular research agendas at the expense of others. As 
Friesen argues (2009), this misses out on other kinds of work that may also be important: work that asks whether we are tackling the right kind of problem in the first place, or who stands to benefit from these developments, for example.

However, this does not mean that practical research is undesirable, or that all work should be theoretical. To suggest that all research in the field should engage with theory is just as ideological as proposing that it should not. Rather, as Freisen (2009) and Czerniewicz (2010) both suggest, the field may be better served by valuing different kinds of work, and developing our capacity to engage with theoretical as well as pragmatic issues. Work that is instrumental is useful, and has its place. So too, however, does work that is interpretive, critical or emancipatory, and these under-represented alternatives need valuing and encouraging so as to counterbalance the increasingly dominant position of theory-free or theory-applying work.

\section{Conclusions}

Research in learning technology has focused on practical, instrumental concerns, to the detriment of its ability to engage with theory. Previous reviews have show that theory has been relatively neglected, with most of those examples that do use theory best characterised as applying it rather than engaging with it in a critical or scholarly way. This situation risks turning the field into a narrow and derivative area of work: at best, only able to draw from other areas; and at worst, only of relevance to those with a vested interest in the specific practical situation currently under study.

This has resulted in many missed opportunities to 'speak back' to theory. Learning technology, as a field, is about more than developing better instructional design processes, and this diversity needs to be recognised and valued. We need to be able to develop theory, question it and even reject it if necessary; we also need to develop the capacity to question whether work in the field serves particular interests rather than others, and whether this is appropriate. Learning technology research could also be used to make connections with other fields. This could be achieved through the integration of theories drawn from other areas; it could also involve serious engagement with and development of the ideas and approaches that are used. Such engagement would demonstrate the relevance of learning technology research to education, psychology and other social sciences, as well as enriching our understanding of the problems that we face.

\section{References}

Barab, S., and K. Squire. 2004. Design-based research: Putting a stake in the ground. Journal of the Learning Sciences 13, no. 1: 1-14.

Bernstein, B. 1977. Class, codes and control. Volume 3. Towards a theory of educational transmissions. London: Routledge and Kegan Paul.

Berry, J. 1997. Immigration, acculturation and adaptation. Applied Psychology: An International Review 46, no. 1: 5-34.

Berry, J. 2005. Acculturation: Living successfully in two cultures. International Journal of Intercultural Relations 29, no. 6: 697-712.

Boyer, E. 1997. Scholarship reconsidered: Priorities of the professoriate. San Francisco: Jossey-Bass.

Chen, R. 2010. Knowledge and knowers in online learning: Investigating the effects of online flexible learning on student sojourners. Doctoral diss., University of Wollongong, Australia. http://ro.uow.edu.au/theses/3099/ (accessed January 6, 2011). 
Clark, R.E. 1983. Reconsidering research on learning from media. Review of Educational Research 53, no. 4: 445-59.

Conole, G., and M. Oliver. 2007. Introduction. In Contemporary perspectives on e-learning research, ed. G. Conole and M. Oliver, 1-18. London: RoutledgeFalmer.

Conole, G., J. Smith, and S. White. 2007. A critique of the impact of policy and funding. In Contemporary perspectives on e-learning research, ed. G. Conole and M. Oliver, 38-54. London: RoutledgeFalmer.

Cook, J. 2002 The role of dialogue in computer-based learning and observing learning: An evolutionary approach to theory. Journal of Interactive Media in Education 5. http:// jime.open.ac.uk/article/2002-5/88.

Czerniewicz, L. 2010. Educational technology - Mapping the terrain with Bernstein as cartographer. Journal of Computer Assisted Learning 26, no. 6: 523-34.

de Freitas, S., and M. Oliver. 2006. How can exploratory learning with games and simulations within the curriculum be most effectively evaluated? Computers \& Education 46: 249-64.

Engeström, Y., J. Virkkunen, M. Helle, J. Pihlaja, and R. Poikela. 1996. The change laboratory as a tool for transforming work. Lifelong Learning in Europe 1, no. 2: 10-7.

Friesen, N. 2009. Rethinking e-learning research. New York: Peter Lang.

Gee, J. 2005. Learning by design: Good video games as learning machines. E-learning 2, no. 1: $5-16$.

Hawkridge, D. 2002. Educational technology research in higher education. Internal report, Open University, Milton Keynes, UK.

Maton, K. 2006. On knowledge structures and knower structures. In Knowledge, power and educational reform: Applying the sociology of Basil Bernstein, ed. R. Moore, M. Arnot, J. Beck, and H. Daniels, 44-59. London: Routledge.

Mayer, R. 1997. Multimedia learning: Are we asking the right questions? Educational Psychologist 32, no. 1: 1-19.

Mayer, R., and P. Chandler. 2001. When learning is just a click away: Does simple user interaction foster deep understanding of multimedia messages? Journal of Educational Psychology 93, no. 4: 806-12.

Mayer, R., and C. Johnson. 2008. Revising the redundancy principle in multimedia learning. Journal of Educational Psychology 100, no. 2: 380-6.

Mayer, R., and R. Moreno. 2003. Nine ways to reduce cognitive load in multimedia learning. Educational Psychologist 38, no. 1: 43-52.

Mayes, J.T. 1995. Learning technology and groundhog day. In Hypermedia at work: Practice and theory in higher education, ed. W. Strang, V.B. Simpson, and D. Slater. Canterbury: University of Kent Press.

McFarlane, A., A. Sparrowhawk, and Y. Heald. 2002. The role of games in education: A research report to the DfES. Cambridge: TEEM. http://www.teem.org.uk.

Oliver, M., and C. Pelletier. 2005. The things we learned on Liberty Island: Designing games to help people become competent game players. Paper presented at DiGRA 2005: The Digital Games Research Association's 2nd International Conference, Changing Views: Worlds in Play, June 16-20, in Vancouver, BC, Canada.

Oliver, M., and C. Pelletier. 2006. Activity theory and learning from digital games: Developing and analytical methodology. In Digital Generations: Children, Young People and New Media, ed. D. Buckingham and R. Willett, 67-88. London: Lawrence Erlbaum.

Pask, G. 1976. Conversation, cognition and learning: A cybernetic theory and methodology. Amsterdam: Elsevier.

Pelletier, C. 2009. Games and learning: What's the connection. International Journal of Learning and Media 1, no. 1: 83-101. http://www.mitpressjournals.org/doi/abs/10.1162/ ijlm.2009.0006.

Pelletier, C., and M. Oliver. 2006. Learning to play in digital games. Learning, Media and Technology 31, no. 4: 329-42.

Reeves, T.C. 1993. Pseudoscience in computer-based instruction: The case of learner control research. Journal of Computer-Based Instruction 20, no. 2: 39-46. 
Reeves, T.C. 2005. No significant differences revisited: A historical perspective on the research informing contemporary online learning. In Online learning: Personal reflections on the transformation of education, ed. G. Kearsley, 299-308. Englewood Cliffs, NJ: Educational Technology Publications.

Reeves, T., J. Herrington, and R. Oliver. 2005. Design research: A socially responsible approach to instructional technology research in higher education. Journal of Computing in Higher Education 16, no. 2: 97-116.

Reigeluth, C.M., and T.W. Frick. 1999. Formative research: A methodology for creating and improving design theories. In Instructional theories and models, ed. C.M. Reigluth, 2nd ed., 633-51. Mahwah, NJ: Lawrence, Erlbaum Associates.

Saettler, P. 1990. The evolution of American educational technology. Englewood, CO: Libraries Unlimited.

Selwyn, N. 2007. The use of computer technology in university teaching and learning: A critical perspective. Journal of Computer Assisted Learning 23, no. 2: 83-94.

Squire, K. 2002. Cultural framing of computer/video games. Game Studies: The International Journal of Computer Game Research 2, no. 1.

Stake, R. 1995. The art of case study research. Thousand Oaks, CA: Sage Publications.

Thorpe, M. 2002. From independent learning to collaborative learning: New communities of practice in open, distance and distributed learning. In Distributed learning: Social and cultural approaches to practice, ed. M. Lea and K. Nicoll, 131-51. London: RoutledgeFalmer.

Yin, R. 2009. Case study research: Design and Methods. 4th ed. Thousand Oaks, CA: Sage Publications. 